\title{
CONFRONTANDO A VULNERABILIDADE E INDEFENSABILIDADE SOCIAL: A EXPERIÊNCIA DA ARTICULAÇÃO NO SEMIÁRIDO BRASILEIRO (ASA).
}

\author{
Uende Aparecida Figueiredo Gomes* \\ João Luiz Pena**
}

\section{Resumo}

Este trabalho tem por objetivo apresentar e discutir as ações do Programa de Formação e Mobilização Social para Convivência com o Semiárido - Um milhão de Cisternas Rurais (P1MC) e o trabalho realizado pela Articulação no Semiárido Brasileiro (ASA). Para avaliar as ações do programa foram realizadas entrevistas abertas com gestor do Ministério do Desenvolvimento Social e Combate à Fome, com membro da coordenação da ASA e com um beneficiário integrante do Movimento dos Trabalhadores Rurais Sem Terra. A análise dos dados indica que as ações da ASA têm sido efetivas ao instituírem práticas de convivência com o semiárido por meio de tecnologias de coleta e armazenamento de água de chuva, no entanto, o fortalecimento político das populações beneficiadas pelas ações ainda permanece como desafio.

Palavras chave: Cisternas, semiárido, água de chuva, P1MC, ASA

\section{CONFRONTING THE VULNERABILITY AND SOCIAL defencelessness: THE EXPERIENCE OF} THE JOINT Brazilian semiarid region (ASA).

\begin{abstract} Key words: Cisterns, semiarid, Rainwater, P1MC, ASA

\section{INTRODUÇÃo}

A Articulação no Semiárido Brasileiro - ASA é uma rede de organizações formada em 1999 durante a realização do Fórum Paralelo da Sociedade Civil à III Conferência das Partes da Convenção das Nações Unidas para o Combate à Desertificação (COP3), realizada em Recife, Pernambuco, Brasil, e, na atualidade, congrega
\end{abstract}

This paper aims to present and discuss the actions of the Program of Training and Social Mobilization for Living with the Semi-arid - One Million Rural Cisterns (P1MC) and the work done by the Brazilian Semiarid Articulation (ASA). To evaluate the actions of the program were made interviews with managers of the Ministry of Social Development and Hunger Alleviation, member of the coordination with the ASA and a beneficiary of the Landless Rural Workers Movement. Content analysis of interviews indicate that the actions of ASA have been to introduce effectives practices of coexistence with the semiarid through technologies for collecting and storing rainwater, however, the political empowerment of the people benefited by the actions still remains a challenge.

mais 700 organizações com atuação no Semiárido Brasileiro. Em 2001, a ASA idealizou o Programa de Formação e Mobilização Social para Convivência com o Semiárido - Um milhão de Cisternas Rurais (P1MC). No ano de 2003, o P1MC ganhou novo impulso ao ser incluído no programa governamental Fome Zero. Neste ano, o P1MC institucionalizouse, sob responsabilidade da Secretaria Nacional de Segurança Alimentar e Nutricional - Sesan do 
Ministério do Desenvolvimento Social e Combate à Fome - MDS. Por meio de um convênio pactuado entre Governo Federal e ASA, a União passou a apoiar e financiar programas de construção de cisternas e formação de multiplicadores (BRASIL, 2008a).

Embora a construção de cisternas de placas $^{1}$ nucleie as ações do P1MC, seus objetivos são mais amplos, uma vez que perpassam a mobilização, participação e formação da população beneficiada para convivência com o semiárido. De acordo com o MDS (BRASIL, 2008b), são objetivos do P1MC:

- Apoiar estados, órgãos federais e sociedade civil atuantes na região semiárida na implementação de programas que visem garantir o acesso à água potável, como componente fundamental da garantia da segurança alimentar e nutricional, para as famílias de baixa renda do sertão nordestino.

- Possibilitar à população do semiárido o acesso a uma estrutura simples e eficiente de captação de água da chuva e de aproveitamento sustentável de recursos pluviais, bem como fomentar a formação e a capacitação para a convivência sustentável com o Semiárido.

- Contribuir com a integração União, Estados, Municípios e Sociedade Civil na implementação de ações que tenham como foco a convivência com o semiárido.

Em dez anos de atuação a rede de entidades executou a construção de 400 mil cisternas de placas no semiárido brasileiro beneficiando, aproximadamente, 1.200 .000 pessoas. A partir de 2007, a ASA ampliou à perspectiva do Programa de Formação e Mobilização Social para Convivência com o Semiárido que passou a englobar dois eixos de atuação. Além do P1MC, um programa voltado para construção de cisternas que armazenam água para consumo humano, a rede de entidades elaborou o projeto Uma Terra e Duas Águas $P 1+2$. De acordo com a ASA, o objetivo do P1+2 é ir além da captação de água de chuva para o consumo humano, avançando para a utilização sustentável da terra e o manejo adequado dos recursos hídricos para produção de alimentos, promovendo a segurança alimentar e a geração de renda (ASA, 2010). O numeral "1" significa terra suficiente para que nela se desenvolvam processos produtivos visando segurança alimentar e nutricional, enquanto que o " 2 " corresponde a duas formas de utilização da água - água potável para cada família do semiárido e água para a produção agropecuária (ASA, 2010).

Para execução do $\mathrm{P} 1+2$, a rede de entidades coloca em prática diferentes tecnologias de captação de água de chuva para a produção de alimentos. Essas tecnologias foram selecionadas a partir de intercâmbios e encontros onde os agricultores familiares apresentam suas experiências. As principais tecnologias implementadas pelo $\mathrm{P} 1+2$ são as cisternas calçadão ${ }^{2}$ e as barragens subterrâneas ${ }^{3}$. Nas Figuras de 1 a 6 são apresentadas etapas dos Programas P1MC e P1+2.

Para Lucas e Hoff (2008), o P1MC e a concepção de trabalho da ASA são importantes no sentido da mobilização social e na fratura que se cria na compreensão estereotipada de seca e da caatinga como algo que deve ser combatido e eliminado. Para as autoras, há uma transformação do "saber-agir sobre o mundo", já que a intervenção é realizada numa perspectiva dos recursos locais. As autoras ainda complementam que, para o habitante do semiárido, aprender a lidar com a seca é uma forma de se tornar cidadão, posto que as cisternas são metáforas de palavra e de ação de indivíduos que podem tomar seu destino nas mãos e criar fraturas nas estruturas tradicionais de dominação política, hídrica e agrária. As mesmas autoras ainda complementam que é importante compreender que o Programa Um Milhão de Cisternas não soluciona todos os problemas da complexa realidade do Semiárido, mas instaura uma concepção mais humana e menos espetacular de atuação junto às minorias simbólicas (LUCAS e HOFF, 2008, p. 14). 
Confrontando a vulnerabilidade e indefensabilidade social:

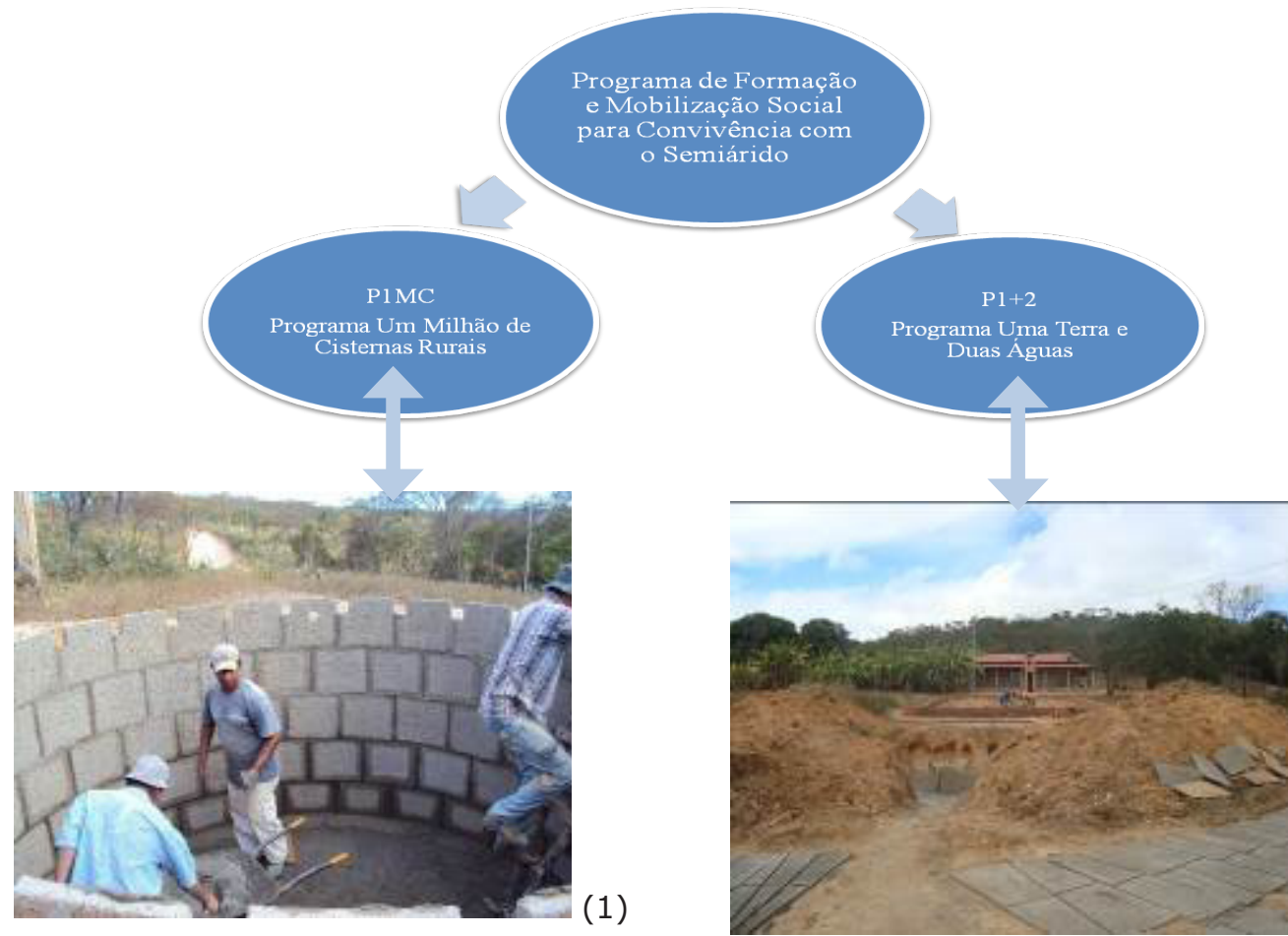

(4)
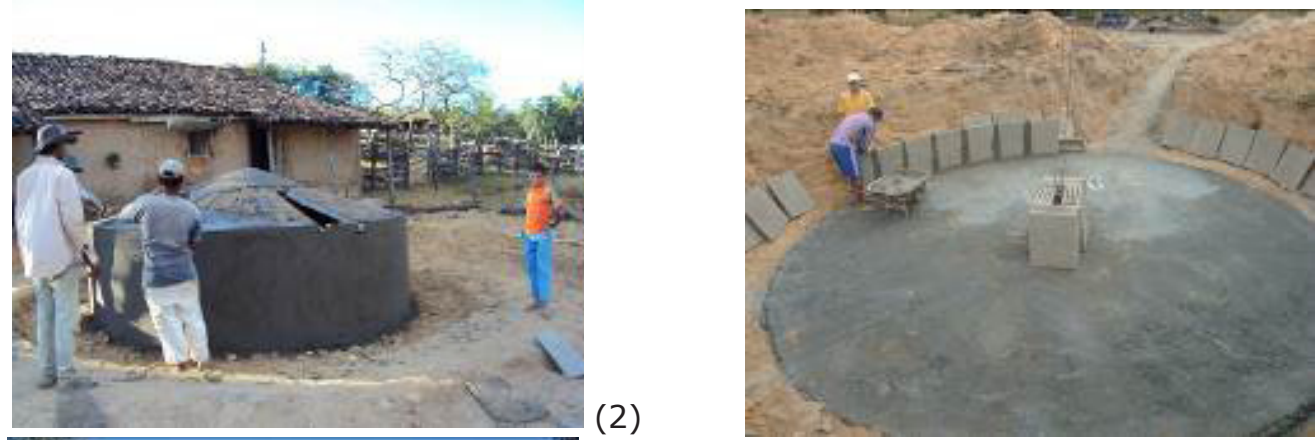

(5)
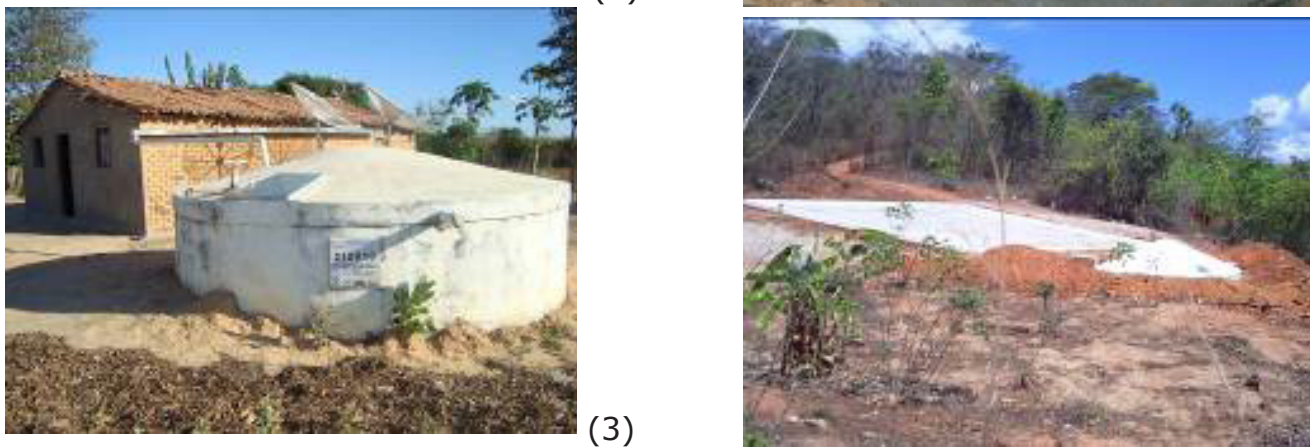
$\mathrm{Na}$ imagem acima, temos:

Figuras 1 e 2: Construção de Cisternas de Placa no município de Serranópolis de Minas, mesorregião Norte de Minas.

Figura 3: Cisterna de placa município de Catuti, mesorregião Norte de Minas, semiárido mineiro.

Figuras 4 e 5: Construção de Cisterna Calçadão no município de Rio Pardo de Minas.

Figura 6: Cisterna Calçadão, município de Chapada do Norte, mesorregião Vale do Jequitinhonha, semiárido mineiro.

Silva (2006) ao analisar as transições paradigmáticas que envolvem as alternativas de desenvolvimento para o semiárido brasileiro contrapondo a perspectiva do combate à seca e as iniciativas de convivência com o semiárido destaca a atuação da ASA na elaboração de propostas que almejam a convivência com o semiárido. Em análise elaborada pelo autor, parte-se do pressuposto de que as práticas governamentais na região semiárida revelam quatro tipos de intervenção: as práticas de assistência emergencial aos flagelados; as ações de combate à seca e seus efeitos; as políticas voltadas à modernização ${ }^{4}$ da base econômica regional, e as práticas alternativas de convivência com o semiárido (SILVA, 2006, p. 27). Para o autor, a visibilidade e a expressão pública da proposta e das práticas de convivência com o semiárido estão sendo conduzidas por novos sujeitos políticos que buscam ampliar os espaços públicos decisórios, de formulação e controle social nas políticas públicas de desenvolvimento regional. O autor ainda complementa que a Articulação no Semiárido Brasileiro expressa a aglutinação desses sujeitos que assumem, atualmente, o protagonismo na defesa de uma política alternativa de desenvolvimento para o semiárido, contrapondo-se a velhas e decadentes oligarquias sertanejas, às forças empresariais que reproduzem a exploração socioambiental da região a ao tecnicismo burocrático do Estado (SILVA, 2006 , p. 269). Na Figura 7 são apresentados fatos importantes dos 10 anos de atuação da ASA.

Ainda que haja um consenso em torno da efetividade das ações da ASA na execução de programas que possibilitam o acesso das famílias a estruturas de captação e armazenamento de água de chuva, o alcance dos objetivos de formação e mobilização social são desafios para as organizações da rede. Além desse aspecto, Galizoni e Ribeiro (2004, p. 9), embora ressaltem a importância do P1MC para promoção e mobilização social com foco na cidadania, afirmam que ao uniformizar o P1MC para todo o semiárido brasileiro ficam diluídas as especificidades internas, diversidades ambientais e culturais. Críticas ao P1MC e ao trabalho da ASA também são apresentadas pelo Tribunal de Contas União - TCU. O TCU realizou, entre os meses de agosto e novembro de 2005 , uma auditoria com o intuito de avaliar o desempenho da ação de construção de cisternas. Segundo o Relatório apresentado pelo TCU, entre 2003 e 2005, o Governo Federal investiu $\mathrm{R} \$ 151,4$ milhões no programa de construção de cisternas (BRASIL, 2006a, p.11). Ainda segundo a auditoria, desse montante, que representa uma parcela do investimento ${ }^{5}, 86 \%$ foram gerenciados pela Associação Programa Um Milhão de Cisternas - AP1MC, uma OSCIP6 (Organização da Sociedade Civil de Interesse Público), criada pela ASA para fins de viabilização de parceria entre a entidade e o Governo Federal. No âmbito da auditoria o TCU 7 constatou que os recursos humanos envolvidos no gerenciamento dos investimentos são inadequados e insuficientes, que os indicadores utilizados pelo MDS (número de cisternas construídas e famílias capacitadas em relação ao total previsto) não são adequados para medir os aspectos relevantes da ação e, ainda, que há falhas no acompanhamento e monitoramento do Programa e na sistemática de distribuição de cisternas (BRASIL, 2006b, p. 18). 


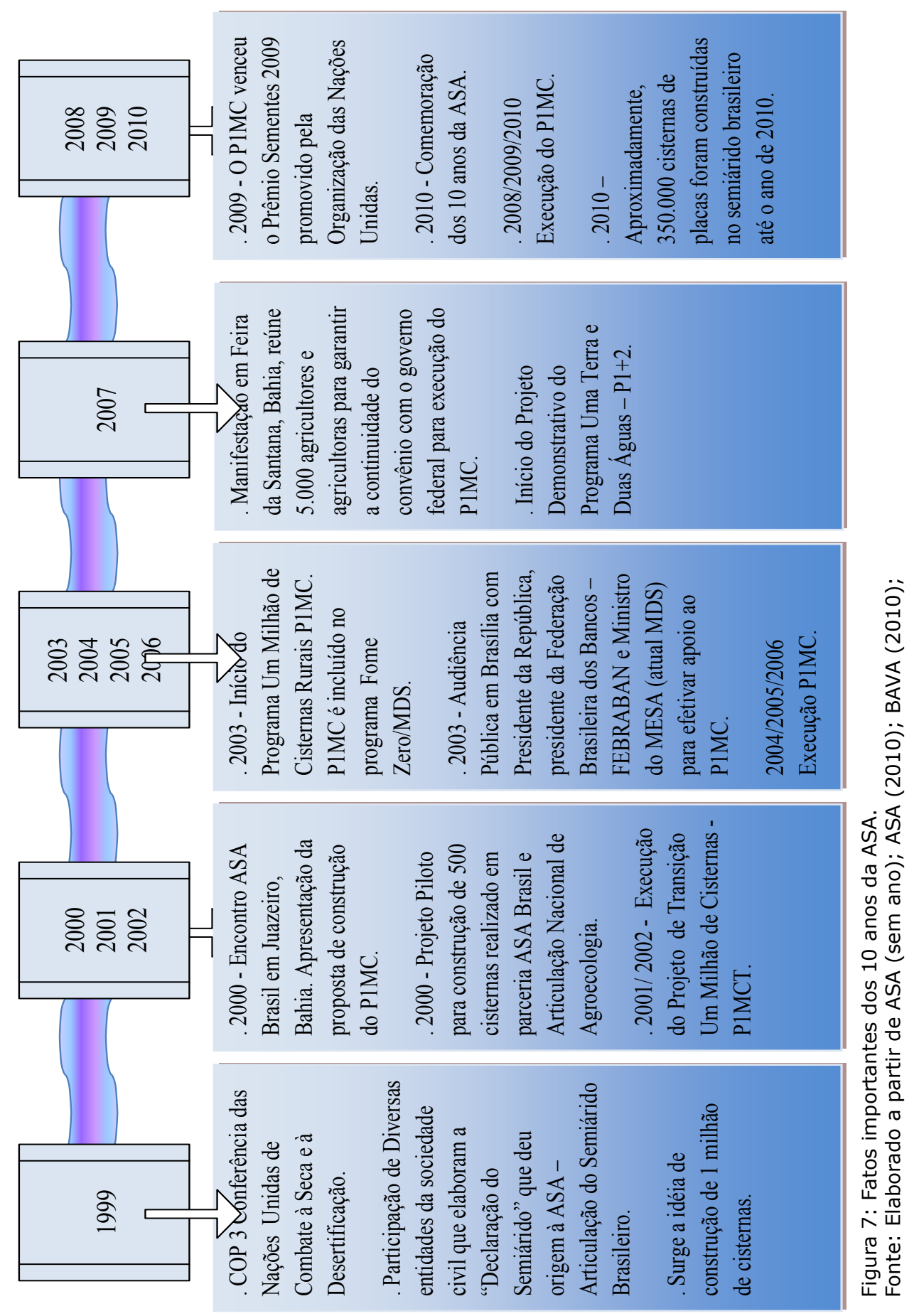


Diante da importância da atuação da ASA na transformação da realidade da região semiárida brasileira e do potencial de seus programas em assegurar segurança hídrica e alimentar para as populações locais, o presente trabalho buscou refletir sobre os limites e possibilidades dos trabalhos da Articulação. Para tanto, as discussões pautaram-se, notadamente, na análise de entrevistas realizadas com três atores de distintas instituições ligadas às ações da ASA: um profissional do Ministério do Desenvolvimento Social e Combate à Fome - MDS, principal agente financiador das ações da ASA, o coordenador da ASA Paraíba e um representante do Movimento dos Trabalhadores Rurais Sem Terra - uma das organizações que compõem a ASA. Os atores foram entrevistados durante o VII Encontro Nacional da ASA realizado em Juazeiro, Bahia entre os dias 21 e 26 de março de 2010. As impressões e observações realizadas durante a participação no evento também compõem a base empírica da análise apresentada.

\section{METODOLOGIA}

No presente estudo, a análise das entrevistas se sustentou nas propostas teóricometodológicas definidas no âmbito da análise de conteúdo. De acordo com Bardin (1994, p. 29), de uma maneira geral, pode-se dizer que os métodos em análise do conteúdo, correspondem aos seguintes objetivos:

- A ultrapassagem da incerteza: no sentido de refletir se o que o pesquisador julga ver na mensagem está lá efetivamente contido, podendo esta visão muito pessoal, ser partilhada por outros. . O enriquecimento da leitura: pela descoberta de conteúdos e estruturas que confirmam (ou não) o que se procura demonstrar a propósito das mensagens, ou pelo esclarecimento de elementos de significações susceptíveis de conduzir a uma descrição de mecanismos de que a priori não se detém a compreensão.

Entre as modalidades de Análise de Conteúdo optou-se pela realização de uma Análise Temática. Segundo Minayo (2007, p. 315), a noção de tema está ligada a uma afirmação sobre determinado assunto. Para Bardin (1994, p. 105), o tema é a unidade de significação que se liberta naturalmente de um texto analisado segundo certos critérios relativos à teoria que serve de guia à leitura. A autora afirma que fazer uma análise temática consiste em descobrir os núcleos de sentido que compõem a comunicação e cuja presença, ou frequência de aparição podem significar alguma coisa para o objeto analítico estudado. Com base nos referencias teóricos da Análise Temática o estudo das entrevistas seguiu os seguintes procedimentos:

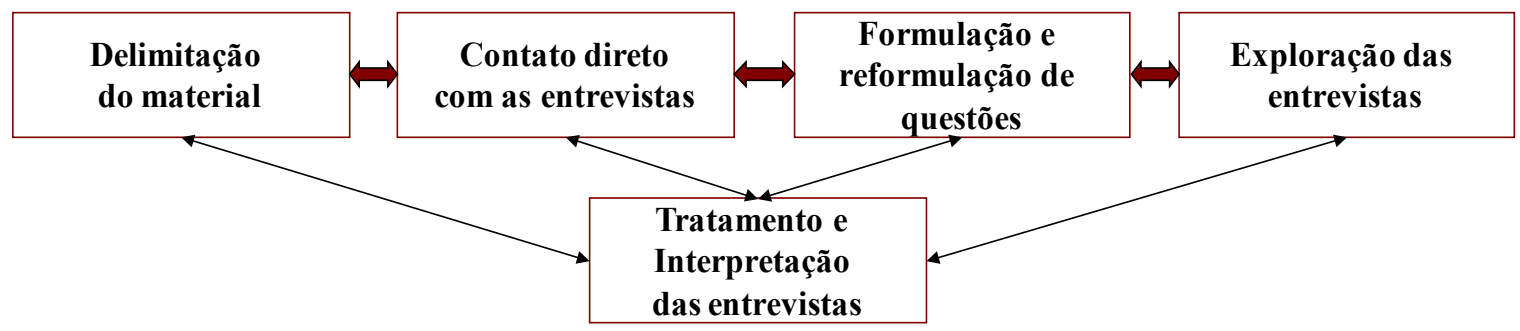

Os temas centrais da análise foram:

1 - A captação de água de chuva, por meio do P1MC, como melhor alternativa de abastecimento de água para consumo humano na região semiárida em contraposição a outros sistemas, em especial, aos sistemas de distribuição de água por meio de redes;
2 - Os Programas da ASA como promotores de mobilização e formação social para convivência com o semiárido;

3 - As intervenções da ASA como promotoras de fortalecimento e geração de autonomia das comunidades beneficiadas. 


\section{RESULTADOS}

Entre os sujeitos entrevistados parece haver um consenso em relação à viabilidade da captação e armazenamento de água de chuva como a melhor alternativa para o abastecimento de água para fins de consumo humano no semiárido, conforme se observa nos discursos a seguir:

MDS/AGENTE GOVERNAMENTAL Pensando no semiárido, ela, essa alternativa, isso no semiárido da zona rural, essa população que o ministério tem alcançado, na minha visão ela é praticamente impossível, onerosa demais, ou seja, não existe essa possibilidade de chegar encanamento com o abastecimento de água pra todas as famílias da zona rural difusa do semiárido. Então pra essas famílias dispersas a solução final tá na captação de chuva e no gerenciamento dessa água seja no solo, seja nos reservatórios... ...Claro que a gente não pode imaginar que só água de beber ela é, aqueles 16 mil litros, ela é a solução final, pra zona rural difusa ela é mais uma questão da concretude da realidade, porque fica oneroso por demais fazer essa, imaginar que a gente vai chegar assim [redes de abastecimento de água]... ...muitos sistemas simplificados de abastecimento vêm da água do subsolo e aí é salobra e aí também não dá para beber, então você vê em alguns lugares pequenos núcleos rurais que têm a água encanada chegando, mas é uma água salobra, então a cisterna tem o seu papel também. Então no sentido assim, ela é realmente uma solução universal, mais abrangente, serve tanto, serve até para cidades, se você for pensar a questão da água de uma maneira mais abrangente, ela é também uma solução, ela é uma prática que tem que ser adotada por, nas suas diversas frentes.

ASA/PARAÍBA Eu particularmente não percebo como viável, quer dizer, não tem viabilidade econômica você pensar em rede de distribuição, com uma escala que você pode ter hoje de rede elétrica, a eletrificação rural... ....Hoje, as estruturas de distribuição hídrica mais, na forma de rede, elas funcionam bem pra áreas de centros urbanos, mas comunidades dispersas como no semiárido, só os custos de manutenção dela inviabiliza. Eu acho que a conta, economicamente, eu não vejo que isso seja um caminho produtivo e ao mesmo tempo, a população difusa, ela tem um privilégio nessa região que é a possibilidade de ter chuvas relativamente abundantes, não chove pouco no semiárido, chove relativamente bem, o problema é que você não tem estrutura de captação e armazenamento de água. O próprio solo, solos rasos não permitem reter a água, a própria taxa de evapotranspiração é muito elevada, então o que cai é rapidamente, o que cai é rapidamente perdido você não tem condições de reter essa água no sistema, ou seja, pra atender a demanda difusa de água, que é da população do semiárido que essa nunca teve rede de abastecimento e eu não acredito que venha a ter, só no entorno de pequenos centros urbanos e pra atender essa demanda difusa só oferta difusa e aí com infraestruturas também difusas e eu acho que tem um potencial imenso...

MST/SEM TERRA Na verdade o P1MC foi um programa que foi muito bom, na área do semiárido... ... tem muita gente que agradece até hoje [o entrevistado foi pedreiro e construiu cisternas no seu assentamento], "ah, aquela caixa que você foi lá fazer tá servindo demais, tem água..." então pra mim assim a ASA que tem dado esse apoio de juntar a água e isso no semiárido, tem sido fundamental pra nós, numa área em que nós, a água pra consumo tem dificuldade, água pra produção tem dificuldade, é de fundamental importância e por isso acho que vai ser de fundamental importância dar sequência no projeto.

Embora os entrevistados abordem aspectos da sustentabilidade do programa e da efetividade deste na percepção dos beneficiários, o aspecto econômico parece ser o centro da análise. Este discurso evidencia a dificuldade de se avançar na construção de um processo coerente com a compreensão de que o acesso à água constitui um direito humano essencial, conforme declarou, recentemente, a Assembléia Geral da Organização das Nações Unidas (ONU) ${ }^{8}$.

Conforme observado pelo agente governamental, a caixa coletora de água de chuva, com capacidade para armazenar 16 mil litros, 
não é a solução final para a população residente de forma difusa na zona rural do semiárido. Assim sendo, fica explicitada a necessidade de investimentos que proporcionem a ampliação do acesso ao abastecimento de água nas áreas rurais do semiárido, o que pode ser alcançado por meio do acréscimo de volume nas estruturas de captação e armazenamento de água de chuva, notadamente, em situações de dispersão populacional, como também pela ampliação do acesso as redes de abastecimento em espaços nos quais a ocupação humana ocorreu de forma menos dispersa em um processo de diversificação das fontes de abastecimento a fim de garantir a segurança hídrica das populações.

A ampliação do acesso ao abastecimento de água não pode estar submetida ao discurso da viabilidade econômica uma vez que este acesso constitui um direito. A realidade do semiárido brasileiro sinaliza para soluções consorciadas de abastecimento de água potável subsidiadas pelo Estado. Nessa perspectiva, para responder ao questionamento sobre o que faz do P1MC a melhor alternativa quando comparada a outras formas de abastecimento de água, notadamente no que se refere ao acesso às redes de abastecimento, é necessária uma reflexão que considere as outras dimensões envolvidas na elaboração e execução do Programa.

Uma análise mais ampla permitiria observar que justificar a escolha do P1MC como melhor alternativa para promoção do acesso à água no semiárido a partir do enfoque economicista desconsidera que o principal objetivo da ASA, como rede executora do $\mathrm{P} 1 \mathrm{MC}$, não é a construção de cisternas de placas e sim a formação e mobilização social para convivência com o semiárido. Formar e mobilizar para convivência com o semiárido não é um processo simples, tampouco, de baixo custo. Feita esta ressalva ainda persiste a indagação em torno dessa questão: uma vez que atingir os objetivos do P1MC envolve processos complexos que demandam investimentos, por que os atores diretamente envolvidos destacam a viabilidade econômica? Possivelmente, porque essa é a realidade da execução do Programa com recursos sendo liberados de forma descontínua e sem uma reflexão crítica em torno das dificuldades de se alcançar os objetivos propostos. Esta situação prejudica as atividades de formação e mobilização que demandam processos contínuos para sua concretização. Por outro lado, é notável que a variável econômica é o principal e, por vezes, o único aspecto considerado na definição das políticas sociais o que justificaria a ênfase dada pelos sujeitos em relação a esta característica. Os entraves para liberação de recursos e a descontinuidades do Programa são abordados pelos sujeitos:

MDS/AGENTE GOVERNAMENTAL $E$ preciso ter uma leitura dupla, eu diria, tranquila não é. Dá muito trabalho, muito vai e vem... há um certo ranço, vamos dizer assim de que certas questões sempre voltam à tona. Então assim, num momento em que a gente poderia dizer que a gente poderia estar caminhando pra uns processos mais ágeis, mais tranqüilos, mais consolidados de repasse desses recursos, não é. Cada ano é uma batalha na burocracia interna... os órgãos jurídicos, os órgãos de controle, as interpretações das leis de diretrizes orçamentárias e por aí vai... todo ano tem esse desafio, de praticamente de voltar a justificar e trazer os elementos que sustentam a proposta. Mas por outro lado, por outro lado, como eu disse, meio bilhão de reais eu não poderia dizer que está ruim, na verdade assim, ele foi um modelo que deu certo de parceira que conseguiu operar um volume de recursos grande, apresentar resultados...

MST/SEM TERRA ...nós tivemos alguns problemas, eu inclusive fiz um curso de pedreiro e ajudei na execução de algumas cisternas e assim, e na mobilização, ajudei na mobilização, não era só pedreiro, mas também mobilizador e assim, eu acho uma importância grande da continuidade, só que parou no município, parece que nós só vamos ser assistidos pelo Guarda-Chuva ${ }^{9}$, mas parece que ainda não está em execução, que tá parado por causa de recurso e nós estamos aguardando e achamos que é uma necessidade mesmo, tem necessidade e é muito importante pra nós o P1MC e agora o $P 1+2$.

No ano de 2007, quando cinco mil 
agricultores e agricultoras se reuniram em Feira de Santana para protestar contra a interrupção do P1MC, estava em curso no Senado brasileiro a proposta de instalação da Comissão Parlamentar de Inquérito destinada a investigar o repasse de recursos do governo federal para organizações não-governamentais (ONGs). Para Bava (2010), a interrupção do financiamento faz parte do jogo de forças no qual setores conservadores tentam incriminar o governo por seu apoio a organizações populares e ONGs. Para o mesmo autor, o objetivo é atacar o governo, porém mais importante é atacar a própria capacidade de organização popular, especialmente de uma articulação regional, no caso, a Articulação no Semiárido Brasileiro.

Silva (2006, p.27) destaca que a afirmação da proposta de convivência com o semiárido não pertence nem ao poder público nem às forças políticas tradicionais locais. Dessa vez, diz o autor, o protagonismo é de alguns órgãos públicos de pesquisa e de um conjunto de organizações sociais (ONGs, Igrejas, sindicatos) que estão constituindo uma forma política emergente no semiárido. No aspecto da formação política, o Coordenador da ASA ressalta o desafio de fazer com que ações locais se insiram em uma reflexão mais ampla a respeito das alternativas de desenvolvimento instituídas hegemonicamente e as contraponha a modelos mais aptos a transformar as realidades proporcionando melhorias na qualidade de vida da população.

ASA/COORDENADOR PARAÍBA Qual é a capacidade que a ação da ASA tem de a um só tempo fortalecer essas experiências locais, mas favorecer que elas sejam base inspiradora para reflexão teórica sobre desenvolvimento, sobre o efetivo ensinamento do que você está fazendo seja capaz de aprofundar os desafios que estão colocados, ou seja, como é que você traz, ao mesmo tempo o debate sobre um modelo de desenvolvimento que se quer construir e ao mesmo tempo ampliar a consciência da população sobre um modelo de desenvolvimento mais hegemônico que acaba jogando na contra corrente desse movimento que a gente está construindo. Então a politização da experiência eu acho que é o objetivo central porque é ela que dá um sentido maior, ou seja, ela nos permite esse enfoque político pedagógico nos permite dar um significado ao trabalho que extrapola a experiência local em si e isso é um desafio permanente nosso, enquanto ASA, como é que a gente consegue projetar essa realidade.

Cabe ressaltar que o P1MC pauta-se no desenvolvimento de um processo de formação política que tem como referência a construção de estruturas de captação de água de chuva, apresentando como objetivo maior a cidadanização da população do semiárido brasileiro. Nesse aspecto, uma orientação importante no trabalho realizado pela ASA refere-se à forma de ação da rede que além de se colocar como agente interlocutor da população rural do semiárido, principalmente no que concerne à captação de recursos, constrói espaços e meios pelos quais esta população tem a possibilidade de participar das discussões, elaborar, apresentar e pôr em prática suas propostas.

\section{CONSIDERAÇÕES FINAIS}

A Articulação no Semiárido Brasileiro tem contribuído para emergência de novos sujeitos e para construção de espaços nos quais propostas de desenvolvimento alternativas às concepções hegemônicas têm sido discutidas, elaboradas e implantadas.

As ações da ASA têm sido efetivas ao instituírem práticas de convivência com o semiárido por meio de tecnologias de coleta e armazenamento de água de chuva. O sucesso dos programas decorre, em grande medida, da sistematização e valorização de experiências desenvolvidas por agricultoras e agricultores das áreas rurais do semiárido, como também, através da realização de intercâmbios nos quais a troca de conhecimentos é potencializada, no entanto, o fortalecimento político das populações beneficiadas pelas ações ainda permanece como desafio.

Observam-se também dificuldades para concretização de parcerias entre as organizações que compõem a Rede e o poder público. Enquanto nas esferas municipal e estadual os obstáculos perpassam o enraizamento de uma cultura política 
clientelista sustentada pelo uso contínuo de carros pipa, na esfera federal o impasse envolve o aparelho burocrático do Estado, com consequente morosidade no repasse de recursos. Por outro lado, setores conservadores da sociedade promovem a criminalização da atuação da sociedade civil organizada.

\section{AGRADECIMENTOS}

Agradecemos ao CNPq - Conselho Nacional de Desenvolvimento Científico e Tecnológico pela concessão da Bolsa de Doutorado e Bolsa de Desenvolvimento Tecnológico e Industrial (DTI), respectivamente à primeira autora e ao segundo autor e pelo financiamento do Projeto: Programa Um Milhão de Cisternas Rurais Uma Avaliação das Dimensões Epidemiológica, Tecnológica e Política Institucional.

\section{Notas}

1. Cisternas de placas são construídas a partir de placas de cimento pré-moldadas, são cobertas e, por meio de um sistema de calhas acoplado aos telhados, recebem e armazenam a água da chuva. As cisternas têm capacidade de armazenar 16.000 litros de água. Galizone e Ribeiro (2004) relatam que as primeiras cisternas de placa foram criadas por Manoel Apolônio de Carvalho que é pedreiro há, aproximadamente, quarenta anos, no município de Simão Dias, no estado de Sergipe.

2. Variação da forma de captação de água de chuva de cisternas de placas. A tecnologia consiste na construção de uma calçada de chão cimentado, inclinado, em uma área de $110 \mathrm{~m}^{2}$. A cisterna calçadão tem capacidade para armazenar $50 \mathrm{mil}$ litros de água.

3. Barragens subterrâneas conservam a água de chuva infiltrada no subsolo mediante uma barragem em profundidade cavada até a camada impermeável do solo.

4. O autor destaca o caráter conservador das políticas de modernização econômica, em especial daquelas elaboradas durante o regime militar e que ainda influenciam as intervenções governamentais. Para o autor, as políticas se submeteram aos interesses das oligarquias locais, representadas pelos grandes pecuaristas, e, sobretudo, aos interesses dos grupos empresariais que passam a investir nos pólos agropecuários da região sob a orientação técnica e autoritária do Estado (SILVA, 2006, p.27).
5. Empresas privadas, organismos internacionais, ONGs, governos estaduais e municipais também representam fontes de alocação de recursos;

6. Organizações civis que obtêm um certificado emitido pelo poder público federal ao comprovar o cumprimento dos requisitos. Lei 9.790 de 23/03/99, também conhecida como Lei do Terceiro Setor;

7. Ressaltamos que a auditoria foi realizada pelo TCU no ano de 2005, portanto, existe uma lacuna de cinco anos na análise dos resultados dos investimentos realizados pelo governo federal. Quanto aos indicadores utilizados para medir a ação da ASA informamos que está em curso no Programa de Pós-Graduação em Saneamento Meio Ambiente e Recursos Hídricos da Universidade Federal de Minas Gerais um projeto de avaliação do P1MC no semiárido mineiro que conta com financiamento do Conselho Nacional de Pesquisa (CNPq) e apoio da ASA Minas.

8. Resolução da Assembleia Geral da ONU aprovada em 28 de julho de 2010. A Resolução recebeu 122 votos a favor, 41 abstenções e nenhum voto contra (ONU, 2010).

9. O Programa Guarda Chuva decorre de um convênio pactuado entre Cáritas Brasileira Regional Minas Gerais, como representante da Articulação no Semiárido Brasileiro (ASA Minas), e a Secretaria de Estado de Meio Ambiente e Desenvolvimento Sustentável (Semad) e visa a construção de 
duas mil cisternas no Norte de Minas e Vale do Jequitinhonha. O projeto, orçado em $\mathrm{R} \$ 4,9$ milhões, também prevê ações de capacitação e recapacitação em Gestão de Recursos Hídricos em comunidades rurais do semiárido mineiro (CÁRITAS, 2009).

\section{Bibliografia}

ASA. Articulação no Semi-Árido. Resultados. Disponível em: http://www.asabrasil. org.br/. Acesso em: 25 de julho de 2011.

ASA. Articulação no Semi-Árido. Programa e Projetos da ASA Minas. Boletin Impresso. Sem ano. BAVA, Sílvio Caccia. Captação de água, construção de cidadania. Jornal Le Monde Diplomatique. Artigo online. Disponível em: http://diplomatique.uol.com.br/ artigo.php? id $=80 \&$ PHPSESSID $=592$ 37801654 ad $08 \mathrm{ff} 5 \mathrm{e} 37 \mathrm{~d} 19 \mathrm{fea}$ ad 491

BARDIN, Laurence. Análise de Conteúdo. Tradução Luis Antero Reto e Augusto Pinheiro. Lisboa: Edições 70, 1994. 226 p. Título original: L'Analyse de Contenu. BRASIL. Ministério do Desenvolvimento Social e Combate à Fome. Secretaria Nacional Alimentar e Nutricional. 2008a. Programa Cisternas: Histórico. Disponível em: http://www.mds. gov.br/programas/seguranca-alimentare-nutricional-san/cisternas/ cisternas-2/ historico. Acesso em: 06 de outubro de 2008.

BRASIL. Ministério do Desenvolvimento Social e Combate à Fome. Secretaria Nacional Alimentar e Nutricional. 2008b. Programa Cisternas: O que é o Programa? Disponível em: http://www. mds.gov.br/programas /seguranca-alimentar-enutricional-san/cisternas/cisternas-2/o-que-e-oprograma. Acesso em: 06 de outubro de 2008.

BRASIL. Tribunal de Contas da União. Relatório de Avaliação de Programa: Ação Construção de Cisternas para Armazenamento de Água. Relator Ministro Guilherme Palmeira. Brasília:

TCU, Secretaria de Fiscalização e Avaliação de Programas de Governo, 2006a. 131 p. Disponível em: http://www2.tcu.gov.br/pls/portal/docs/ PAGE/ TCU/CONTROLE EXTERNO/FISCALIZACAO/
AVALICAO PROGRAMAS GOVERNO/RELATORIOS/ CISTERNAS.PDF. Acesso em: 06 de outubro de 2008.

BRASIL. Tribunal de Contas da União. Avaliação da Ação Construção de Cisternas para Armazenamento de Água. Sumários Executivos. Relator Ministro Guilherme Palmeira. Brasília: TCU, Secretaria de Fiscalização e Avaliação de Programas de Governo, 2006b. 44 p. CÁRITAS. Convênio em Minas Gerais beneficiará duas mil famílias. Disponível em: http://www.caritas. org. br/noticias. php? code $=13 \&$ id $=546 \&$ filtro $=6$. Acesso em 10 de set. 2009 .

GALIZONE, Flávia Maria; RIBEIRO, Eduardo Magalhães. Notas sobre água de chuva: o Programa Um Milhão de Cisternas no semi-árido mineiro. In XIV ENCONTRO NACIONAL DE ESTUDOS POPULACIONAIS, 2004, Caxambu. Caxambú, ABEP: 2004. LUCAS, Luciane; HOFF, Tânia. A face oculta da caridade: linhas de força e de fratura do discurso midiático do bem. In XVII ENCONTRO DA ASSOCIAÇÃO NACIONAL DE PÓS-GRADUAÇÃO EM COMUNICAÇÃO, 2008, Curitiba-PR. Curitiba-PR, compós: 2008. MINAYO, Maria Cecília de Souza. O desafio do conhecimento: pesquisa qualitativa em saúde. 10. ed. São Paulo: Hucitec, 2007. 406 p.

ONU. Organização das Nações Unidas. ONU diz que acesso à agua potável é direito humano. Disponível em: http://www.unmultimedia.org/radio/portuguese/ detail/182780.html. Acesso: 30 de jul. de 2010. SILVA, Roberto Marinho Alves. Entre o Combate à Seca e a Convivência com o Semiárido: transições paradigmáticas e sustentabilidade do desenvolvimento. Tese de doutorado. Centro de Desenvolvimento Sustentável, Universidade de Brasília. Brasília, 2006, 248 p. 
